Thorax (1976), 31, 49.

\title{
Acute aortic dissection and medial degeneration in patients with 'floppy' mitral valves
}

\author{
ROXANE M C A Y a nd MAGDI H. YACOUB \\ The Cardiothoracic Surgical Unit, Harefield Hospital, Middlesex
}

\begin{abstract}
McKay, Roxane and Yacoub, M. H. (1976). Thorax, 31, 49-54. Acute aortic dissection and medial degeneration in patients with 'floppy' mitral valves. Mitral regurgitation due to 'floppy' valves is frequently associated with areas of medial necrosis in the ascending aorta. Application of the aortic clamp to such an area during valve replacement may produce an intimal tear followed by acute dissection. This complication occurred in three patients and was treated successfully by repair of the tear in the two cases where the dissection was observed at the time of operation. It is suggested that infrequent clamping of the aorta and careful control of the perfusion pressure may decrease the risk of intimal trauma and acute dissection.
\end{abstract}

Medial degeneration is known to underlie dissecting aneurysms associated with the Marfan syndrome and aortic valve lesions, but the importance of similar changes in the ascending aorta of patients with mitral valve disease is not generally appreciated. We report three cases of acute dissection of the aorta occurring during or immediately after cardiopulmonary bypass for replacement of 'floppy' mitral valves, and measures to prevent this potentially lethal complication are discussed. Although there was no radiographic evidence of aortic disease preoperatively and macroscopically the vessels appeared normal, histological examination revealed areas of elastic disruption or mucoid degeneration. The clinical presentation of the floppy valve syndrome (Read, Thal, and Wendt, 1965) and the appearance of the valve at the time of operation (McKay and Yacoub, 1973) are sufficiently characteristic for patients in whom this complication is likely to occur to be identified.

\section{CASE REPORTS}

CASE 1 A 46-year-old milkman first sought medical attention for fatigue and an irregular heart beat. He gave no history of rheumatic fever, and cardiac examination 13 years earlier had been normal. The only abnormal finding on examination was a late systolic murmur, but over the next six years he suffered progressive fatigue, dyspnoea on exertion, and, eventually, paroxysmal nocturnal dyspnoea. Although there was no history suggestive of infective endocarditis or myocardial infarction and the patient remained in sinus rhythm, he developed florid signs of congestive failure. The murmur now was found to have become pansystolic. Response to digitalis and diuretics was satisfactory, and the haemodynamic findings at cardiac catheterization were only mildly abnormal (Table). A left ventricular cineangiogram, however, showed grade $3 / 4 \mathrm{mitral}$ regurgitation into a slightly enlarged left atrium; aortic root injection showed no valvular incompetence or vascular abnormality. The patient re-

T A B L E

CARDIAC CATHETERIZATION FINDINGS IN THREE PATIENTS UNDERGOING REPLACEMENT OF 'FLOPPY' MITRAL VALVES

\begin{tabular}{|c|c|c|c|c|c|}
\hline Case & $\begin{array}{l}\text { Mean Pulmonary } \\
\text { Wedge Pressure }\end{array}$ & $\begin{array}{c}\text { Pulmonary Wedge } \\
\text { 'V'-wave }\end{array}$ & $\begin{array}{c}\text { Pulmonary Artery } \\
\text { Pressure }\end{array}$ & $\begin{array}{l}\text { Left Ventricular } \\
\text { Pressure }\end{array}$ & $\underset{\text { Index }}{\text { Cardiac }}$ \\
\hline $\begin{array}{l}1 \\
2 \\
3\end{array}$ & $\begin{array}{r}2 \\
23 \\
10\end{array}$ & $\begin{array}{r}3 \\
35 \\
13\end{array}$ & $\begin{array}{l}15 / 5 \\
46 / 21 \\
66 / 28\end{array}$ & $\begin{array}{l}125 / 0 \\
115 / 20 \\
105 / 0\end{array}$ & $\frac{2 \cdot 0}{1 \cdot 8}$ \\
\hline
\end{tabular}

Pressures are in millimetres of mercury. Cardiac index is given as $1 / \mathrm{min}$ per square metre. 
mained fairly well on medical treatment for 10 months but suddenly decompensated again with the onset of atrial fibrillation. At recatheterization the mean pulmonary wedge pressure had increased to $8 \mathrm{mmHg}$ at rest and rose to $22 \mathrm{mmHg}$ after one minute of exercise. The remaining right heart pressures were within normal limits, but the cardiac index had decreased to $1.71 / \mathrm{min}$ per square metre.

The findings at operation in September 1969 were consistent with mitral regurgitation into a markedly dilated left atrium. The mitral valve was exposed through a transseptal approach: the valve ring was grossly dilated with attenuated cusp tissue and ruptured chordae between the anterior cusp and the posteromedial papillary muscle. The valve was excised and replaced by a fresh aortic homograft (Yacoub and Kittle, 1969). On discontinuing bypass, it became apparent that there was an acute dissection of the aorta, so bypass was re-established and the ascending aorta was explored. The dissection was found to start at the level of the aortic clamp, where there were two intimal tears. These were repaired with Teflon buttresses on the outside, and bypass was discontinued without incident. Postoperatively the patient made an uncomplicated recovery.

Cardiac catheterization six months after valve replacement showed good function of the homograft and no evidence of the dissection. During five and a half years follow-up the patient has shown no sign of congestive heart failure or aortic dissection.

Histology of the aortic wall showed mucoid medial degeneration; the elastica appeared normal.

CASE 2 A retired plasterer underwent the first of 31 hospital admissions for congestive heart failure at the age of 54 years. He was said to have had rheumatic fever as a child but had previously engaged in active sports and served seven years in the Royal Air Force without cardiac symptoms. Despite treatment with digoxin and diuretics, his mitral regurgitation became steadily incapacitating, until he required oxygen therapy at rest. On physical examination at the age of 70 he was weak and dyspnoeic with mild peripheral cyanosis and signs of severe congestive heart failure: the first heart sound, normal in intensity, was followed by a loud pansystolic murmur in the mitral area, and the liver was palpable $6 \mathrm{~cm}$ below the right costal margin. Chest radiographs substantiated gross enlargement of the heart, with dilatation of upper lobe veins. The electrocardio- gram showed atrial fibrillation with runs of junctional tachycardia, complete right bundle- 음 branch block, and frequent ventricular ectopic $\overline{\bar{\alpha}}$. beats. Lung function tests showed a pattern $\stackrel{\mathbb{Q}}{\complement}$ typical of restrictive lung disease, with a forced expired volume in one second of $1.371 / \mathrm{min}$; $a^{\infty}$ lung scan was normal. At catheterization (Table) $\vec{\circ}$ there were no gradients across the mitral or aortic $\overrightarrow{\vec{\omega}}$ valves. The left ventricular cavity appeared small $\stackrel{\omega}{\omega}$ on an angiogram, with marked mitral regurgita- $\overrightarrow{\vec{\partial}}$ tion into a very large left atrium. Aortic root $\underset{\omega}{x}$ injection showed no aortic regurgitation and the proximal coronary arteries appeared normal.

The patient underwent aortic homograft replace- $\vec{c}$ ment of the mitral valve and tricuspid annulo- $\frac{}{-}$ plasty in August 1971. All four chambers of the $\overrightarrow{-}$ heart were massively enlarged with very poor $\mathbb{D}$ contractility; there was aneurysmal dilatation of $\frac{\mathrm{O}}{\mathrm{C}}$ the non-coronary sinus of Valsalva into the right atrium and aneurysmal enlargement of the left atrium. The left atrium was opened behind $\vec{\theta}$ Sondesgaard's sulcus, disclosing a stretched mitral valve with thin spidery chordae but no obvious rupture. The valve was excised and replaced by a fresh aortic homograft. The left atrium was plicated to reduce its size, and bypass was discontinued. As the heart action remained poor $\stackrel{\mathbb{Q}}{\mathbb{Q}}$

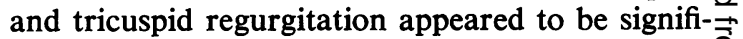
cant, bypass was reinstituted and tricuspid $\frac{\circ}{3}$ annuloplasty was performed through the right atrium. Bypass was discontinued again but, despite reduction of the tricuspid regurgitation, the heart took the load of the circulation with difficulty. Postoperatively persistent bleeding $\underset{\times}{\stackrel{\vec{D}}{\vec{N}}}$ necessitated exploration of the sternotomy. Despite supportive measures, cardiac output 3 . deteriorated, and the patient died 36 hours after operation.

At necropsy the heart was very large witho hypertrophy of both the left and right ventricles. The inverted homograft in the mitral position was intact and the aortic valve showed no gross $\frac{\mathrm{N}}{\mathrm{N}}$ abnormality. In the aorta there was a dissecting. aneurysm starting as a $7-\mathrm{cm}$ transverse tear, $N$ $5.5 \mathrm{~cm}$ above the valve and extending nearly to స్ట the diaphragm. Sections of the mitral valve re- 0 moved at operation showed marked myxomatous degeneration of both the cusp margins and the chordae tendineae.

CASE 3 A 52-year-old company director was first noted to have a heart murmur when admitted to hospital for haemoptysis. There was no history of $\mathbb{Q}$ rheumatic fever nor family history of hearto disease, and the remainder of his cardiac examina- 
tion, save for a blood pressure of $160 / 116 \mathrm{mmHg}$, was within normal limits. A chest film showed an opacity in the right lung field which proved to be an encysted lobar effusion at thoracotomy. He was readmitted to hospital one year later in severe congestive failure, although still in sinus rhythm. After treatment with digitalis the patient resumed his former activities, free of symptoms, for over four years. While on holiday at the age of 57 , he suddenly became breathless, and despite control of his hypertension and intensive diuretic treatment he deteriorated rapidly over a period of three months. There was no history of chest pain, haemoptysis or fever. On examination the patient was breathless after minimal effort, in atrial fibrillation with a pulse of 80 and blood pressure of $160 / 90 \mathrm{mmHg}$. There was a loud pansystolic murmur in the mitral area accompanied by a thrill. Cardiac catheterization (Table) documented the presence of pulmonary hypertension, and on the cineangiogram there was pronounced regurgitation of contrast into an enlarged left atrium. There was no aortic regurgitation or gross abnormality of the aortic root.

At operation in October 1970, all four chambers of the heart were enlarged with poor myocardial contractility. The left atrium was opened behind Sondesgaard's sulcus, displaying a dilated mitral ring with prolapse of the posterior cusp due to rupture of three major chordae from the anterolateral papillary muscle. The valve was replaced by a fresh, inverted aortic homograft. As the final suture line was being completed in the floor of the atrium, a dissection of the ascending aorta was noted to begin at the site of the aortic clamp and to progress rapidly toward the aortic ring. The aorta was clamped higher immediately, and transverse aortotomy showed a large, transverse, intimal tear at the former site of the aortic clamp. This was repaired by multiple interrupted mattress sutures supported by Teflon felt on the outside. Bypass was discontinued without incident. The patient's postoperative recovery was uneventful.

Seven months after valve replacement the patient was reinvestigated. $\mathrm{He}$ had neither symptoms nor signs of congestive failure or dissecting aneurysm. Catheterization measurements showed good function of the homograft but moderate impairment of left ventricular function. Pulmonary vascular resistance was 6 units. On contrast studies, the 'mitral' valve was totally competent and there was no evidence of aortic dissection. In four and a half years' follow-up there has been no change in this patient's con- dition, although he has required intensive antifailure and antihypertensive therapy.

Histology of the mitral valve (Fig. 1) and the aortic wall (Figs 2 and 3 ) showed moderate mucoid degeneration.

\section{DISCUSSION}

Acute dissection of the aorta has been reported as an infrequent but serious complication of cardiopulmonary bypass, beginning most often at the site of femoral or iliac cannulation in association with severe atherosclerosis (Matar and Ross, 1967). Dissection also has originated proximal to the cannulae in arteriosclerotic vessels or those involved by cystic medial degeneration (Elliot and Roe, 1965). In these cases, the tear was attributed to high velocity retrograde perfusion. Cannulation of the ascending aorta for arterial return reduces the risk of such complications, but in the present examples, where arterial return was to the ascending aorta, dissection began at the site of the aortic clamp rather than the arterial cannulae. In over 1000 bypass operations using this method at Harefield Hospital, there has been no other instance of dissection. It is of interest that the only other reported case of a dissection starting at the site of aortic clamping occurred during mitral valve replacement for isolated mitral regurgitation (Salama and Blesovsky, 1970). These observations suggested the possibility of a coincident vascular abnormality, and, in fact, a significant degree of medial degeneration was found on microscopic examination of aortic biopsies from our three patients. The ascending aorta was biopsied in eight other patients, who subsequently underwent replacement of 'floppy' mitral valves without complication, and four showed increased mucopolysaccharides with elastic disruption of the media.

Medial degeneration was observed first at necropsy in ruptured aneurysms (Gsell, 1928; Erdheim, 1929) and later found to be invariably present in a large series of unruptured dissections (Gore and Seiwert, 1952) as well as in a significant number of routine necropsy specimens (Rottino, 1940). It is now accepted that myxomatous degeneration predisposes to dissection and rupture of the aorta in the Marfan syndrome (Murdoch et al., 1972) and its 'forme fruste' or annulo-aortic ectasia (Chapman et al., 1965). Similar pathology has been described in the aorta of patients with the Marfan syndrome who suffer isolated mitral regurgitation (Raghib et al., 1965; Simpson, Nora, and McNamara, 1969). While none of our three patients displayed skeletal 
FIG. 2. Case 3. Aortic wall showing increased basophilic staining material in the media (Haematoxylin and eosin $\times 60$ ).

FIG. 1. Case 3. Mitral valve cusp and chordae, showing mucoid degeneration of cusp and disruption of the core of the chorda (in section) with deposition of myxomatous material around it (Alcian blue $\times 45)$.

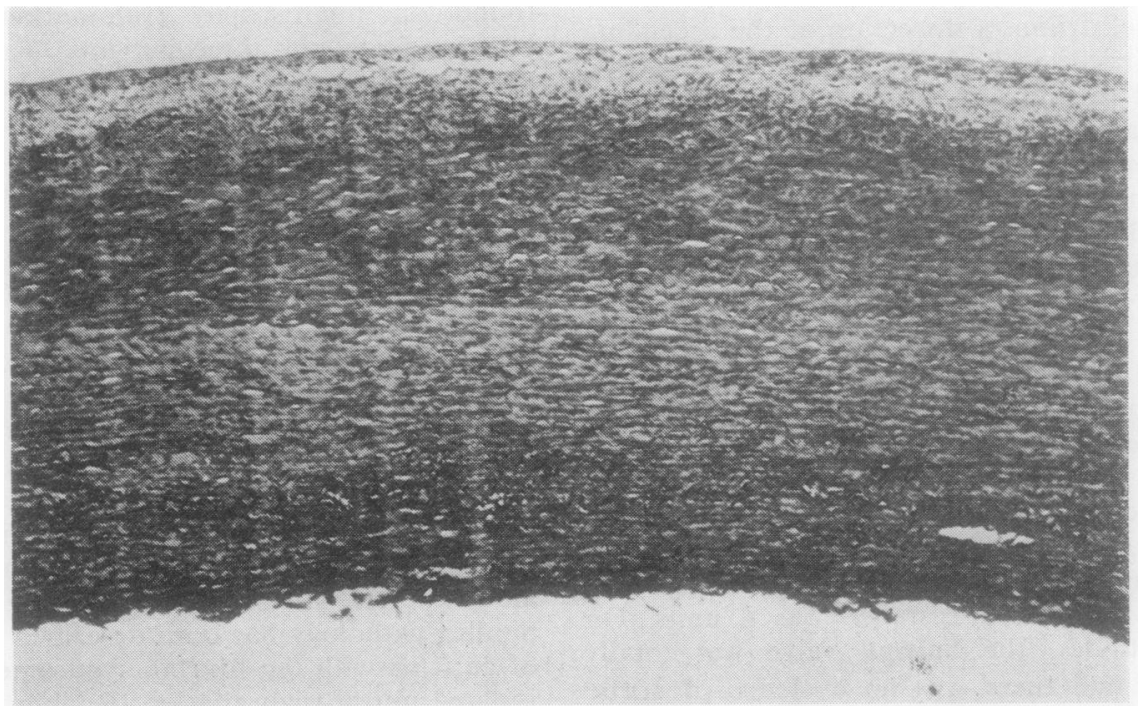




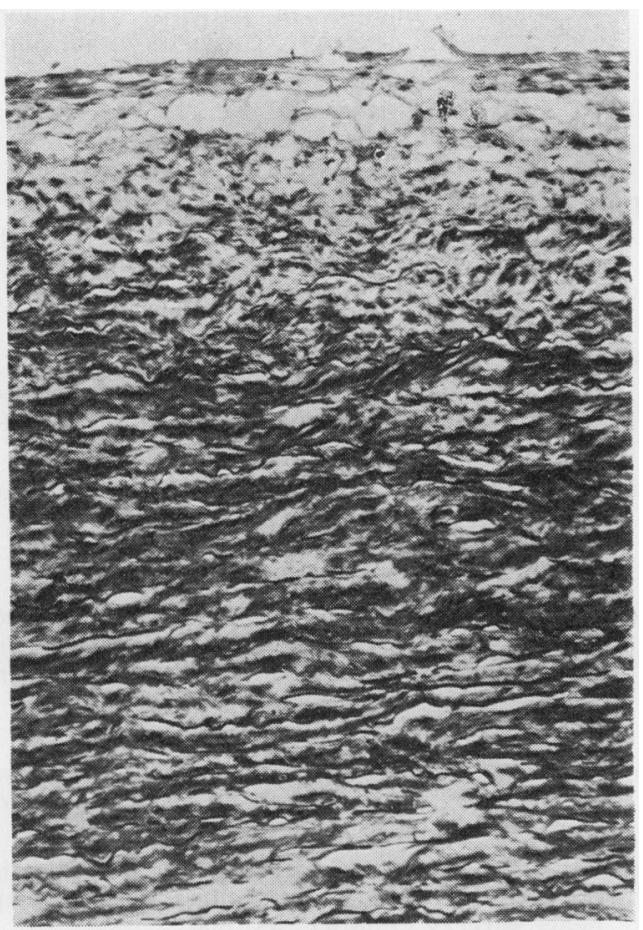

FIG. 3. High-power magnification of aortic wall stained for elastic tissue with Weigert elastic-van Gieson stain (X140).

stigmata of the Marfan syndrome, their valves were typically 'floppy' with diffuse myxomatous change on microscopic examination.

At operation a 'floppy' mitral valve (Fig. 4) characteristically prolapses into the atrium with soft, redundant cusps and elongated or ruptured chordae tendineae (Read et al., 1965; Bittar and Sosa, 1968; McKay and Yacoub, 1973). Gelatinous in consistency, the valve becomes thickened by the deposition of mucopolysaccharide material on the cusps and chordae, and endocardial friction lesions may develop on the ventricular surface (Salazar and Edwards, 1970). Preoperatively the diagnosis is suggested in a patient who suffers the unexplained, sudden onset or insidious progression of congestive heart failure in his fifth or sixth decade, usually preceded by many years by an asymptomatic heart murmur. The mitral murmur is most often pansystolic, but it may stimulate an ejection murmur of aortic stenosis when chordae to the posterior cusp have ruptured (Osmundson, Callahan, and Edwards, 1958) or occur late in systole with limited prolapse of one

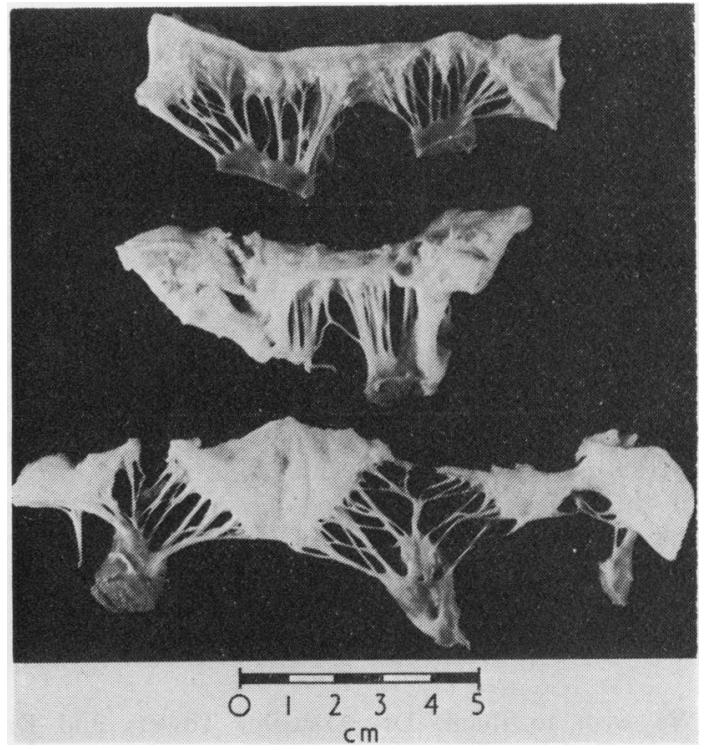

FIG. 4. 'Floppy' mitral valve (bottom) showing the large, voluminous cusps and elongated chordae, with rupture of several chordae attaching the posterior cusp to the posterior medial papillary muscle. This is contrasted with a rheumatic mitral valve (middle) and a normal postmortem specimen (top).

or both cusps (Barlow et al., 1968). The prolapsing leaflets result in varying degrees of mitral regurgitation into a small left atrium (Sanders et al., 1965; Sanders et al., 1967); but, even with an incapacitating degree of mitral regurgitation, the majority of patients remain in sinus rhythm. A spectrum of the different clinical and pathological syndromes which can result from 'floppy' mitral valves has been described (Yacoub and McKay, 1973). Although neither ECG nor haemodynamic findings are diagnostic, ventricular extrasystoles, abnormal $Q$ waves or $\mathrm{S}-\mathrm{T}$ segments in the inferior leads, a large ' $v$ ' wave in the capillary wedge pressure, and a significant reduction in cardiac output are seen frequently in this condition. Angiography confirms the presence of gross mitral regurgitation with variable impairment of left ventricular contractility but only occasionally demonstrates any abnormality of the ascending aorta.

In these three cases the intimal tear resulted from the trauma of an aortic clamp applied to an area with underlying medial degeneration. While it is difficult to estimate the exact incidence and extent of abnormality in the wall of the aorta in patients with 'floppy' mitral valves, from our 
observations and those of others (Rottino, 1940) it would appear that a majority are likely to have at least localized areas of medial degeneration. Application of an aortic clamp as infrequently as possible reduces the chance of traumatizing such an area. In addition, the strain applied to the aorta by the clamp is directly proportional to the perfusion pressure, particularly at the time of application of the clamp. It is suggested, therefore, that the perfusion pressure should be monitored carefully on bypass and any degree of elevation treated by vasodilators. Conversely, a reduced cardiac output may delay the development of a dissection following intimal trauma into the immediate postoperative period, as occurred in one of these patients. When recognized, as it was in the other two, the lesion can be effectively treated by repair of the intimal tear with excellent prognosis.

We wish to thank Dr. Malcolm Towers and Dr. Keith Ball for the pre and postoperative investigation of these patients. Photographic plates for Figs 1-3 were prepared in the Department of Anatomy of the Royal College of Surgeons, London, and Fig. 4, by the photographic department at Mount Vernon Hospital, Northwood, Middlesex.

\section{REFERENCES}

Barlow, J. B., Bosman, C. K., Pocock, W. A., and Marchand, P. (1968). Late systolic murmurs and non-ejection ('mid-late') systolic clicks. British Heart Journal, 30, 203.

Bittar, N. and Sosa, J. A. (1968). The billowing mitral valve leaflet. Circulation, 38, 763.

Chapman, D. W., Beazley, H. L., Peterson, P. K., Webb, J. A., and Cooley D. A. (1965). Annuloaortic ectasia with cystic medial necrosis; diagnosis and surgical treatment. American Journal of Cardiology, 16, 679.

Elliot, D. P. and Roe, B. B. (1965). Aortic dissection during cardiopulmonary bypass. Journal of Thoracic and Cardiovascular Surgery, 50, 357.

Erdheim, J. (1929). Medionecrosis aortae idiopathica. Virchows Archiv für pathologische Anatomie, 273, 454.

Gore, I. and Seiwert, V. J. (1952). Dissecting aneurysm of the aorta: pathological aspects; an analysis of eighty-five fatal cases. Archives of Pathology, 53, 121.

Gsell, O. (1928). Wandnekrosen der Aorta als selbständige Erkrankung und ihre Beziehung zur Spontanruptur. Virchows Archiv für pathologische Anatomie, 270, 1.
McKay, R. and Yacoub, M. H. (1973). Clinical and pathological findings in patients with 'floppy'응 valves treated surgically. Circulation, 48, Supple- $\overline{-\bar{s}}$ ment 3, p. 63 .

Matar, A. F. and Ross, D. N. (1967). Traumatic $\varrho$ arterial dissection in open-heart surgery. Thorax, 22, 82.

Murdoch, J. L., Walker, B. A., Halpern, B. L., Kuzma, J. W., and McKusick, V. A. (1972). Life $\vec{\omega}$ expectancy and causes of death in the Marfan $\%$ syndrome. New England Journal of Medicine, $\underset{\times}{\vec{x}}$ 286, 804.

Osmundson, P. J., Callahan, J. A., and Edwards, J. E.. (1958). Mitral insufficiency from ruptured chordae. tendineae simulating aortic stenosis. Proceedings $\overrightarrow{0}$ of the Mayo Clinic, 33, 235.

Raghib, G., Jue, K. L., Anderson, R. C., and Edwards, J. E. (1965). Marfan's syndrome with mitral in-T1 sufficiency. American Journal of Cardiology, 16, $\mathbb{O}$ 127.

Read, R. C., Thal, A. P., and Wendt, V. E. (1965) Symptomatic valvular myxomatous transformation (the floppy valve syndrome), a possible formece fruste of the Marfan syndrome. Circulation, 32, హ) 897.

Rottino, A. (1940). Medial degeneration, cystic variety, in unruptured aortas. American Heart Journal, 19, 330.

Salama, F. D. and Blesovsky, A. (1970). Complications气 of cannulation of the ascending aorta for openo heart surgery. Thorax, 25, 604.

Salazar, A. E. and Edwards, J. E. (1970). Friction 3 lesions of ventricular endocardium. Archives of Pathology, 90, 364.

Sanders, C. A., Austen, W. G., Harthorne, J. W. Dinsmore, R. E., and Scannell J. G. (1967). Diagnosis and surgical treatment of mitral re gurgitation secondary to ruptured chordae ten $x$ dineae. New England Journal of Medicine, 276, 943.

, Scannell, J. G., Harthorne, J. W., and Austen, W. G. (1965). Severe mitral regurgitation secon dary to ruptured chordae tendineae. Circulation , 31, 506.

Simpson, J. W., Nora, J. J., and McNamara, D. G음 (1969). Marfan's syndrome and mitral valve disease: acute surgical emergencies. American Heart Journal, 77, 96.

Yacoub, M. H., and Kittle, C. F. (1969). A new technique for replacement of the mitral valvew by a semilunar valve homograft. Journal ot Thoracic and Cardiovascular Surgery, 58, 859.

Yacoub, M. H. and McKay, R. (1973). The spectrum of floppy mitral valve syndromes: a clinico pathological study. (Abstract). British Heart Journal, 35, 886.

Requests for reprints to: Dr. Roxane McKay, Hilling don Hospital, Uxbridge, Middlesex. 